\title{
Primers based on tara and quebracho tannins for poorly prepared steel surfaces
}

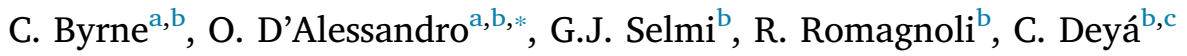 \\ ${ }^{a}$ Departamento de Química, Facultad de Ciencias Exactas, Universidad Nacional de La Plata, 47 y 115 s/no, La Plata, Buenos Aires, Argentina

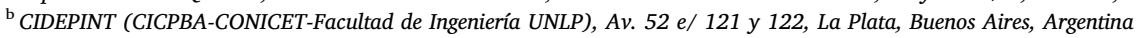 \\ ${ }^{\mathrm{c}}$ Departamento de Ingeniería Química, Facultad de Ingeniería, Universidad Nacional de La Plata, 1 y $47 \mathrm{~s} / n^{\circ}$, La Plata, Buenos Aires, Argentina
}

\section{A R T I C L E I N F O}

\section{Keywords:}

Primers

Lanthanum

Tannins

Poorly surface preparation

Electrochemical tests

\begin{abstract}
A B S T R A C T
Steel panels must be protected during storage and transportation because they can corrode. This protection used to be afforded by chromate primers, but nowadays tannin-based primers are being studied. These primers are not only used as protection but also as adhesion promoter if the steel surface was not well prepared (presence of oxides or low roughness).

The objective of this work was to prepare lanthanum "tannate", employing tara and quebracho tannins. The "tannates" were incorporated in primers formulation and applied on steel SAE 1010 panels (previously exposed to the humidity chamber or with $6 \mu \mathrm{m}$ of roughness depth). These primed panels were exposed to humidity chamber where corrosion and blistering degrees were evaluated. Adhesion test were done. Electrochemical assays such as ionic resistance and corrosion potential measurements were carried out.

Results showed that the adhesion and the barrier properties of the primers were good. Besides, on low roughness steel, the primers diminished the corrosion current.

Results were compared with traditional zinc tetroxychromate primer.
\end{abstract}

\section{Introduction}

Atmospheric corrosion of steel structures leads to the formation of several oxides and oxyhydroxides onto the metal surface [1]. Two layers may be distinguished in these oxide films: a superficial and loose one, and another internal and compact. In the superficial layer, the dominant species are polymorphs of $\mathrm{FeOOH}$, especially lepidocrocite $(\gamma$-FeOOH$)$ and goethite $(\alpha-\mathrm{FeOOH})$ [1]. Lepidocrocite is the first corrosion product to be formed in atmospheres with low chloride concentration. Lepidocrocite gradually converts to goethite, a thermodynamically stable form [2]. Below this layer, where the access of oxygen is limited, black compounds, mainly magnetite $\left(\mathrm{Fe}_{3} \mathrm{O}_{4}\right)$, are formed $[1,2]$. These oxide layers formed on steel make painting difficult and diminish paint performance due to its bad adhesion to the substrate. As a consequence, many studies were done in order to find protective coatings that can be applied on marginally prepared substrates. The main function of temporary pretreatments, or primers, is to protect metals during storage and transportation [3]. These primers must be easily removed and/or must be compatible with the coating system that will protect the substrate during its service life. However, if storage is too long or the atmospheric conditions are aggressive, the primer can be damage and it must be removed before painting [3]. Pretreatments designed to coat rusted substrates frequently contain tannins [4].

Tannins are polyphenolic compounds of vegetable origin that have been widely used as corrosion inhibitors of steel [5-7]. Their stability depends on temperature, solvent, particle size, etc.; a suitable extraction plan can be vary for different plant species [8]. Several research works are concerned with the application of tannins on rusted steel [9-13]. The following tannins were employed: mangrove (Rhizophora apiculate) [10], mimosa (Acacia mearnsii) [13], pine [5], oil palm (Elaeis guineensis) [14] and tara (Caesalpinia spinosa) [9,15]. Rahim et al. studied in several papers steel treated with different solutions of tannins [10-12]. In Rahim et al., 2011, the compounds formed during the interaction between mangrove tannin and pre-rusted iron were studied; they claimed that lepidocrocite was converted into ferric-"tannate" [10]. Rahim et al., 2007, studied the mechanism of steel corrosion protection afforded by the flavonoids monomers present in mangrove tannin [12] and in Rahim et al., 2008, steel protection by mangrove and mimosa tannins in phosphoric acid solutions at different $\mathrm{pH}$ was studied. Results showed that the protection depends on the type of tannin and on the $\mathrm{pH}$ of the solution [11].

\footnotetext{
* Corresponding author at: CIDEPINT (CICPBA-CONICET-Facultad de Ingeniería UNLP), Av. 52 e/ 121 y 122, La Plata, Buenos Aires, Argentina.

E-mail address: o.dalessandro@cidepint.gov.ar (O. D'Alessandro).
} 
On the other hand, Flores et al. studied the incorporation of tara tannin in primer formulation applied on rusted steel; an alkyd top-coat was applied on the primered samples. Results showed that better performance was observed when the waterborne tannin primers were used instead of alkyd pure system [9]. In Hadzich et al., zinc "tannate" was studied in primer and anticorrosive paint formulations; in the case of the primer, the anticorrosive behaviour was similar to that obtained in primers containing second generation zinc phosphate [15].

The presence of aromatic rings with hydroxyl groups in ortho positions made the tannin capable to chelate iron and other metallic cations. In the case of $\mathrm{Fe}^{+3}$, a dark blue, highly insoluble complex, called ferric "tannate" is formed [16-18]. As ferric "tannate" can change the active layer of oxides in a highly crosslinked protective network, tannins are considered as oxides converters [19]. The anticorrosion properties of tannins make their incorporation in primers for rusted steel very promising.

In previous research, the precipitation of tara or red quebracho (Schinopsis lorentzii) tannins with a lanthanum salt was carried out $[20,21]$. The protective action of these lanthanum "tannates" was corroborated and it has two contributions. On the one hand, the previous mentioned effect of tannins as oxide converters and, on the other, the slowly release of small amounts of lanthanum with the later formation of the slightly soluble $\mathrm{La}(\mathrm{OH})_{3}$ on the metal surface. This precipitation occurs on cathodic areas which alkalinize during the corrosion process.

The objective of this work was to study the temporary protection afforded by tara and quebracho tannins and their lanthanum derivatives in primers to be applied on poorly prepared steel surfaces, such as low roughness ones $(\mathrm{Rt}=6 \mu \mathrm{m})$ and rusted substrates. A primer formulated with zinc tetroxychromate was used as control [22]. The primers were assessed by accelerated (exposition to humidity chamber) and electrochemical tests (corrosion potential, ionic resistance and corrosion current density).

\section{Experimental procedure}

\subsection{Preparation and characterization of the metal substrates}

The selected substrate was SAE 1010 steel. Panels $(100 \mathrm{~mm} \times 75 \mathrm{~mm}$ $\mathrm{x} 1 \mathrm{~mm}$ ) were previously degreased with isopropyl alcohol and, then, exposed in the humidity chamber (ASTM D 2247) for 20 days. These panels were allowed to dry for $24 \mathrm{~h}$ in laboratory conditions (20 $\pm 2{ }^{\circ} \mathrm{C}$; $\left.\mathrm{RH} 70 \%\right)$. The oxide layer formed on these samples was characterized by Fourier Transform Infrared Spectroscopy (FTIR) employing the $\mathrm{KBr}$ technique and a Perkin Elmer Spectrum One Spectrometer. The scanned wavelength range was comprised between 400 and $4000 \mathrm{~cm}^{-1}$.

Similar panels only degreased with isopropyl alcohol were also used. The total height of the roughness profile (Rt) of these panels, measured with a Hommel Tester T1000E, was $6 \pm 2 \mu \mathrm{m}$.

\subsection{Preparation of lanthanum "tannates"}

Tannins solutions were prepared from the commercial powders of tara (T40, INDUNOR) and quebracho (UNITAN CROWN ATO) tannins $[20,21]$. The powders were extracted for $1 \mathrm{~h}$ with distilled water at $90{ }^{\circ} \mathrm{C}$. The extracts were vacuum filtered. $\mathrm{KNO}_{3} 1 \mathrm{M}$ was employed to coagulate colloidal particles in the quebracho extract [21].

In order to prepare lanthanum "tannates", the extracts were put in contact with $\mathrm{La}\left(\mathrm{NO}_{3}\right)_{3} 0.1 \mathrm{M}$ and the $\mathrm{pH}$ adjusted to 8.0 with $\mathrm{NaOH}$ $1 \mathrm{M}$, under constant stirring for $1 \mathrm{~h}[20,21]$. The precipitated obtained was washed with distilled water and dried at $100^{\circ} \mathrm{C}$ for $24 \mathrm{~h}$.

\subsection{Formulation, preparation and characterization of the primers}

The primers were formulated in a two-pack system to be mixed just before application, being the A/B ratio4/1 by weight. Pack A contained the anticorrosive pigment $2.21 \% \mathrm{v} / \mathrm{v}$ (tannins, lanthanum "tannate" or zinc tetroxychromate as control pigment), the filler $0.47 \% \mathrm{v} / \mathrm{v}$ (talc), a prime pigment $0.05 \% \mathrm{v} / \mathrm{v}$ (carbon black), the resin $8.18 \% \mathrm{v} / \mathrm{v}$ (polyvinyl butyral, BUTVAR ${ }^{\circ}$ ) and the solvents (isopropyl alcohol $64.06 \% \mathrm{v} / \mathrm{v}, \mathrm{n}$ butyl alcohol $22.89 \% \mathrm{v} / \mathrm{v}$ and water $2.14 \% \mathrm{v} / \mathrm{v}$ ) [20,21]. The components of the Part A were dispersed in a $1 \mathrm{~L}$ ball mill for $24 \mathrm{~h}$ to achieve a dispersion degree of 5 in the Hegman's gage. Solvents (isopropyl alcohol $68.9 \% \mathrm{v} / \mathrm{v}$ and water $14.0 \% \mathrm{v} / \mathrm{v}$ ) and citric acid $17.1 \% \mathrm{v} / \mathrm{v}$ were mixed to obtain Pack B. Citric acid was used to replace the traditional phosphoric acid in order to avoid the precipitation of the insoluble lanthanum phosphate $\left(\mathrm{pK}_{\mathrm{sp}}=27.92\right)$ [23].

A set of steel panels were degreased with isopropyl alcohol and coated with the primers, by brush, up to a dry film thickness of $8 \pm 2$ $\mu \mathrm{m}$. The film thickness was measured with a Schwyz SC117-02 Coating Thickness Gauge.

The steel samples previously rusted in the humidity chamber were wiped off with a steel brush in order to remove the loosely superficial oxides; only adherent oxides were left. Afterwards, they were degreased with isopropyl alcohol and abraded with an emery paper $n^{\circ} 400$. Finally, they were cleaned again with isopropyl alcohol and painted, by brush, up to a final thickness of $8 \pm 2 \mu \mathrm{m}$.

The primed panels were kept under laboratory conditions for 4 days before testing.

The primers containing tannins were labelled as $\mathrm{T}$ and $\mathrm{Q}$ for tara and quebracho tannin respectively. The primers containing lanthanum "tannate" were labelled as TL and QL for tara and quebracho "tannates", respectively. Zinc tetroxychromate primer was named as Z. The degreased substrates were labelled as $\mathrm{D}$ while $\mathrm{O}$ was used for the rusted ones (Table 1).

\subsection{Evaluation of the primers}

Two painted panels of each primer were kept under laboratory conditions $\left(20 \pm 2{ }^{\circ} \mathrm{C}\right.$; $\left.\mathrm{RH} 70 \%\right)$ for a week to obtain their FTIR spectra.

A set of three of each type of primed panels was placed in the humidity chamber (ASTM D 2247) in order to evaluate the blistering degree (ASTM D 714), the rusting degree (ASTM D 610) and adhesion (ASTM D 3359) along time. The degreased samples were removed after 5 days due to the important corrosion process developed on them while the rusted samples were kept in for 7 days.

Electrochemical assessment of primed panels was carried out by means of D.C. electrochemical techniques. The employment of these techniques was justified by the low ionic resistance of the primer film $[24,25]$. D.C. tests are easy to perform and provide valuable and direct information about a system which degrades as time elapse.

Electrochemical tests were done by delimiting a $3 \mathrm{~cm}^{2}$ area on the panel by fixing an acrylic cylinder on it. The cell was filled with $0.1 \mathrm{M}$ $\mathrm{NaCl}$ as electrolyte. The ionic resistance was measured using a Pt counter electrode and an ATI ORION model 170 conductimeter which operates at $1000 \mathrm{~Hz}$. The corrosion rate of primed steel was determined by the linear polarization technique ( $\pm 30 \mathrm{mV}$ from open circuit potential) with a Gamry Interface 1000 potentiostate, employing a typical

Table 1

Panels' nomenclature.

\begin{tabular}{llll}
\hline \multirow{2}{*}{ Pigment } & \multicolumn{2}{l}{ Substrate } \\
\cline { 3 - 4 } & & Degreased (D) & \multirow{2}{*}{ Rusted (O) } \\
\hline \multirow{2}{*}{ Tannins } & Tara (T) & TD & TO \\
& Quebracho (Q) & QD & QO \\
Lanthanum “tannate" & Tara (TL) & TLD & TLO \\
& Quebracho (QL) & QLD & QLO \\
Zinc tetroxychromate (Z) & & ZD & ZO \\
Steel without primer (blank, B) & BD & BO \\
\hline
\end{tabular}




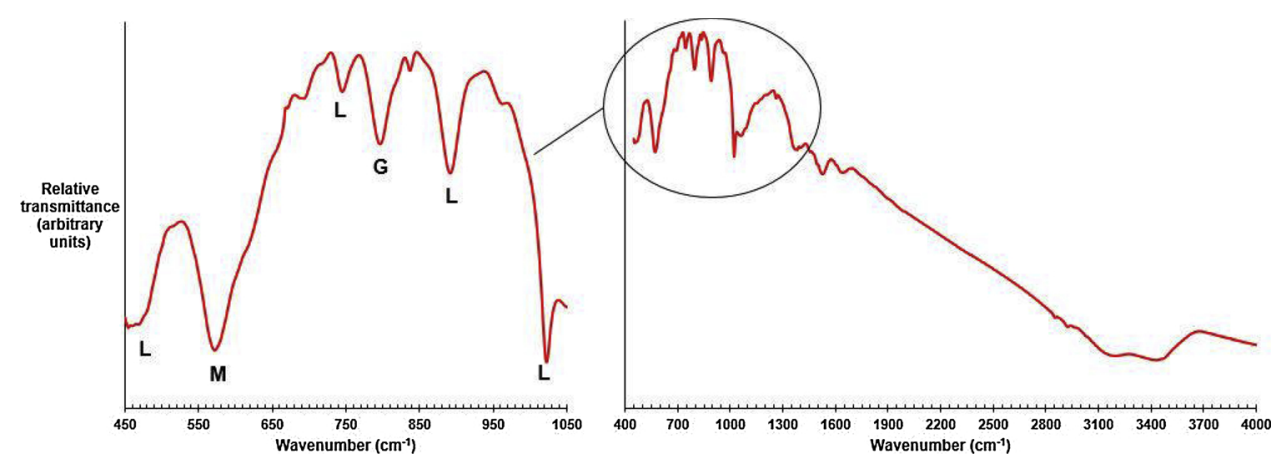

Fig. 1. The FTIR spectra of the oxides. L: lepidocrocite, M: magnetite, G: goethite.

three electrodes cell (a Pt counter electrode, a saturated calomel electrode as reference and the primed steel as the working electrode). The scan rate was $1 \mathrm{mV} / \mathrm{s}$ and the IR compensation mode was used. Corrosion current density (Jc) was determined by the software Gamry Echem Analyst Version 6.33.

\section{Results}

\subsection{Preparation and characterization of metal substrates}

The FTIR spectrum of the superficial oxide layer formed on steel panels in the humidity chamber is shown in Fig. 1. Lepidocrocite has two characteristic bands that corresponds to the librational $\mathrm{OH}$ modes, at $1023 \mathrm{~cm}^{-1}$ (in plane) and $746 \mathrm{~cm}^{-1}$ (out of plane) [12,26]. Goethite has two intense hydroxyl deformation bands at $892 \mathrm{~cm}^{-1}$ and $798 \mathrm{~cm}^{-1}$, which are assigned to the $\delta(\mathrm{OH})$ and $\gamma(\mathrm{OH})$ vibrations, respectively [12,27]. Magnetite has a characteristic band at $572 \mathrm{~cm}^{-1}$ that can be assigned to the Fe-O stretching mode of the tetrahedral and octahedral sites [12,28].

The photographs of the rusted panels' surface before (a) and after (b) cleaning can be seen in Fig. 2. The cleaning process left the black layer, rich in magnetite, exposed. The magnetite layer thickness was measured with a Schwyz SC117-02 Coating Thickness Gauge, and found to be between 5 and $40 \mu \mathrm{m}$.

\subsection{Evaluation of the primers}

\subsubsection{FTIR analysis}

Fig. 3 shows the FTIR spectra of the T primed panels. The spectra of

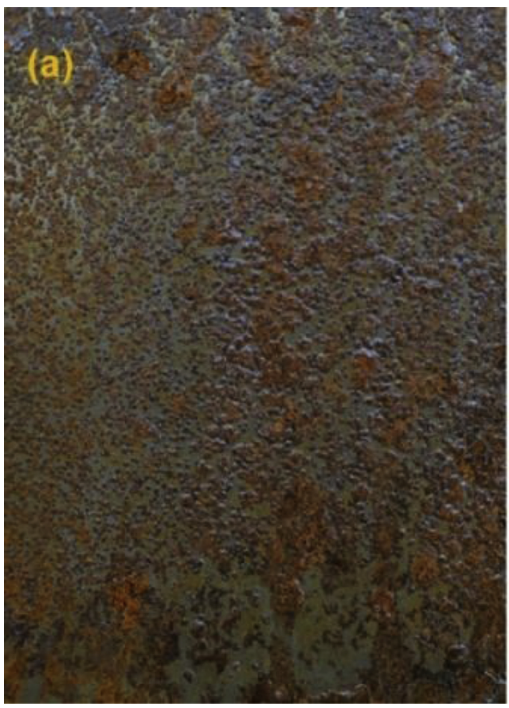

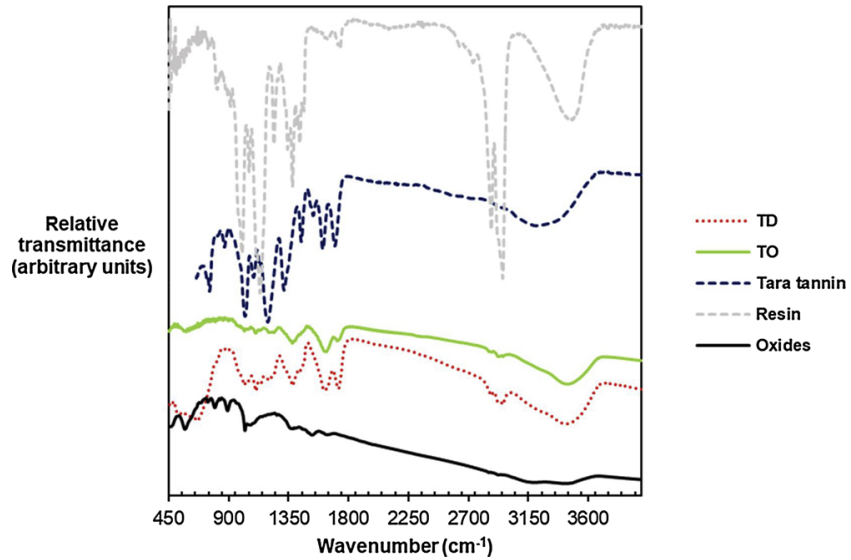

Fig. 3. FTIR spectra of $T$ primed steel panels. Reference spectra: tara tannin, polyvinyl butyral resin and superficial oxide layer of rusted steel panels.

the tara tannin, the resin and the superficial oxide layer of rusted steel panels are also shown as references. In the case of the tara tannin primer on the degreased substrate (TD) no evidence of oxides formation could be seen. However, the spectrum of the rusted SAE 1010 steel primed with tara tannin (TO) showed bands corresponding to lepidocrocite, goethite and magnetite; this last one with low intensity. The broad absorption band between 3000 y $3700 \mathrm{~cm}^{-1}$ which was present in TD and TO spectra can be attributed to the stretching of phenolic $\mathrm{OH}$ groups in tara tannins $[9,12,29,30]$ and to $\mathrm{OH}$ from the polyvinyl butyral resin.

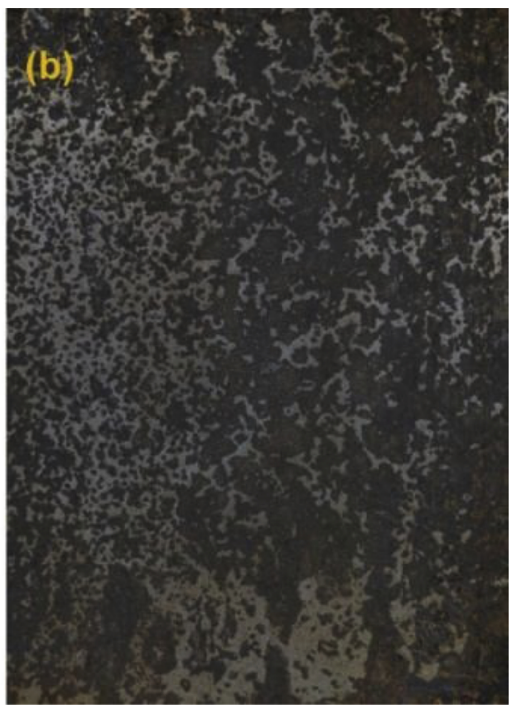

Fig. 2. Oxidized SAE 1010 steel panels before (a) and after (b) the cleaning treatment. 


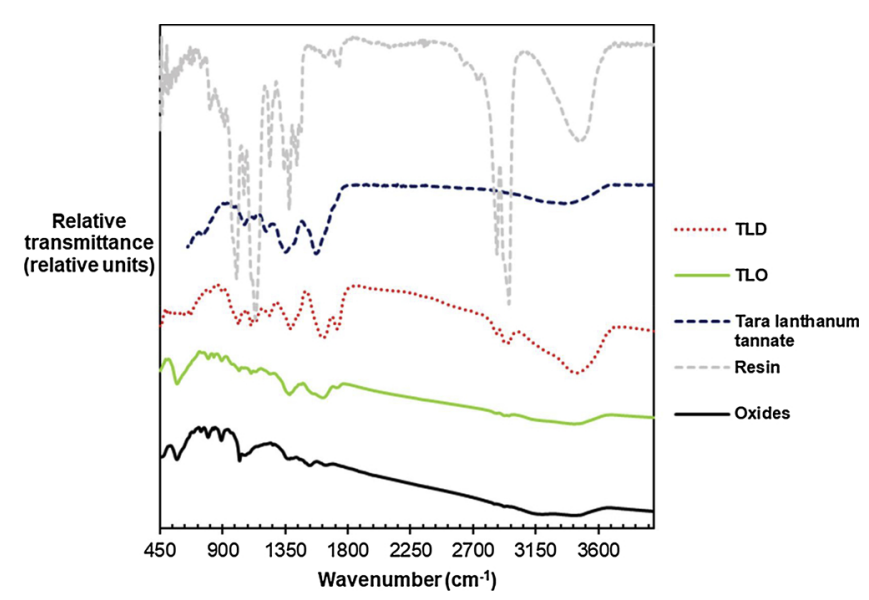

Fig. 4. FTIR spectra of TL primed steel panels. Reference spectra: tara lanthanum "tannate", polyvinyl butyral resin and superficial oxide layer of rusted steel panels.

Fig. 4 depicts the FTIR spectra of TL primed panels together with those of tara lanthanum "tannate", polyvinyl butyral resin and the rusted substrate. The spectrum of TLO presented the bands corresponding to lepidocrocite $\left(1020 \mathrm{~cm}^{-1}\right)$, goethite $\left(799\right.$ and $\left.894 \mathrm{~cm}^{-1}\right)$ and magnetite $\left(575 \mathrm{~cm}^{-1}\right)$. In every case, the presence of these absorption bands would indicate that the conversion of the oxide layer was not complete [13]. In the TLD spectrum a weak band of lepidocrocite at $1020 \mathrm{~cm}^{-1}$ could be seen, while the other above-mentioned bands appeared at the level of the spectral noise. This fact indicated that corrosion was incipient.

The FTIR spectra of the Q primed panels are shown in Fig. 5. The reference spectra are also shown. In the case of the degreased substrate (QD) there is no evidence of the formation of oxides while on the oxidized sample (QO) bands corresponding to lepidocrocite and magnetite are also present but they appeared to be very weak; thus pointing out a greater conversion of the oxide layer.

Fig. 6 contains the FTIR spectra of QL primed panels together with the reference spectra. QLD coated panels showed no evidence of oxide formation, while the spectrum of QLO presented low intensity bands corresponding to magnetite and lepidocrocite.

According to these experimental results it seemed adequate to conclude that the primers protected steel from rusting during exposition in the laboratory atmosphere and that the primers transformed partially the oxide layer by chelating the ionic species of iron $[7,31]$.

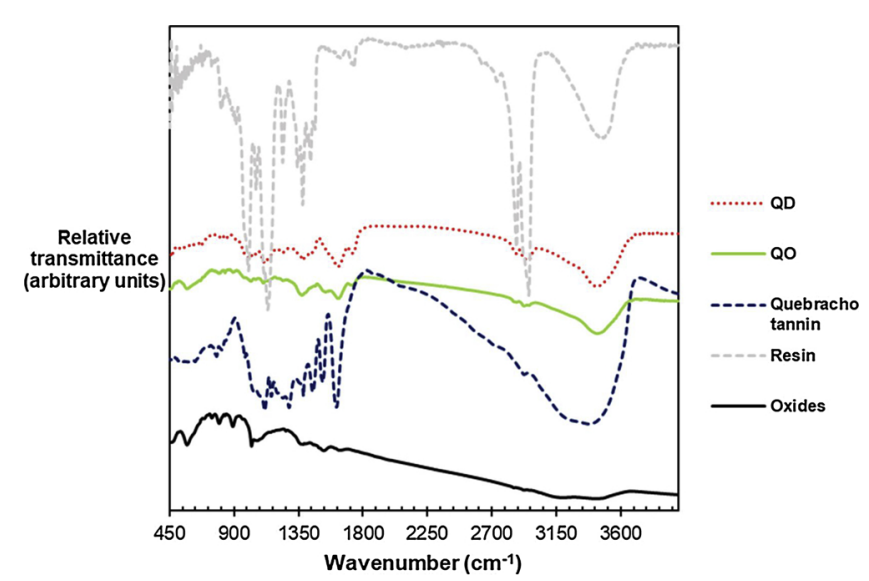

Fig. 5. FTIR spectra of Q primed steel panels. Reference spectra: quebracho tannin, polyvinyl butyral resin and superficial oxide layer of rusted steel panels.

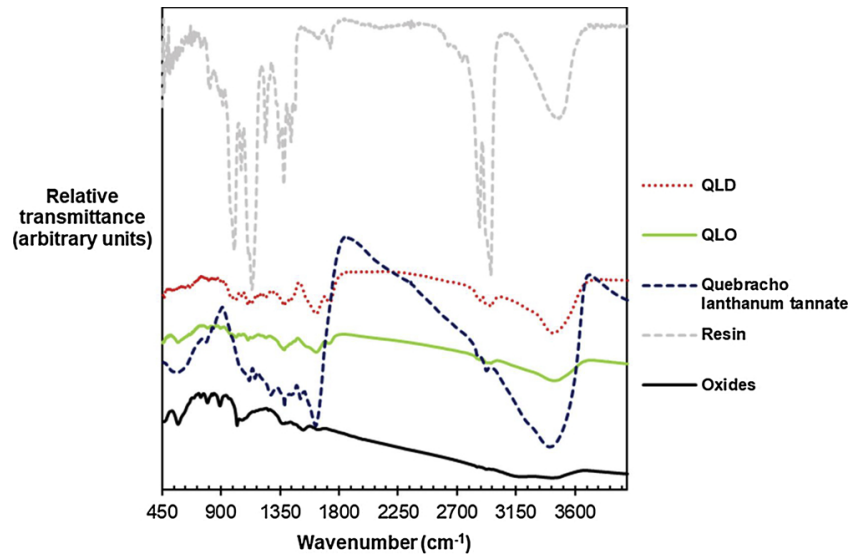

Fig. 6. FTIR spectra of QL primed steel panels. Reference spectra: quebracho lanthanum "tannate", polyvinyl butyral resin and superficial oxide layer of rusted steel panels.

\subsubsection{Humidity chamber}

3.2.2.1. SAE 1010 steel panels without primer. The steel panels without primer (BD) were covered with rust almost completely after 1 day in the chamber (Supplementary data, Fig. I), while the rusted steel (BO) was covered by reddish oxides practically from the beginning of the test (Supplementary data, Fig. II).

3.2.2.2. SAE 1010 steel panels coated with tara primers. The protective behavior of the tara tannin primer (TD) was better than that of the tara lanthanum "tannate" primer (TLD). After 3 days in the chamber, they were qualified with 5 and 4 respectively (Table 2, Supplementary data, Figs. III and IV). This behavior could be explained considering that the interaction of $\mathrm{T}$ with the substrate is stronger than that of TL.

Both previously rusted panels (TO and TLO) were qualified with 6 after 3 days in the humidity chamber (Table 2, Supplementary data, Figs. V and VI).

All the samples presented no blisters along the essay (Table 2).

At the beginning of the test, the adhesion of the tara-based primers to the substrate was good in every case, qualification 4B (Table 2). However, while the adhesion of TD primer remained constant after 4 days of exposure, the system TLD exhibited a gradual loss as time elapsed. This fact could be attributed to the intense reaction of TD with the base metal to form the conversion layer. The primed panels TO and TLO experienced a gradual loss up to three days of exposition, followed by a recovering, matching the qualification 3B after 7 days. The recovering in the adhesion values may be the result of a progressive

Table 2

Humidity chamber. Rusting degreeand adhesion by the tape test.

\begin{tabular}{|c|c|c|c|c|c|c|c|c|c|c|}
\hline \multirow{3}{*}{ Samples } & & \multirow{2}{*}{\multicolumn{4}{|c|}{$\begin{array}{l}\text { Rusting degree } \\
\text { (ASTM D 610) } \\
\text { Time (days) }\end{array}$}} & \multirow{2}{*}{\multicolumn{5}{|c|}{$\begin{array}{l}\text { Adhesion } \\
\text { (ASTM D 3359) } \\
\text { Time (days) }\end{array}$}} \\
\hline & & & & & & & & & & \\
\hline & & 1 & 3 & 5 & 7 & 0 & 1 & 3 & 5 & 7 \\
\hline \multirow[t]{2}{*}{ Without primer } & $\mathrm{BD}$ & 0 & 0 & 0 & - & - & - & - & - & - \\
\hline & $\mathrm{BO}$ & 1 & 0 & 0 & 0 & - & - & - & - & - \\
\hline \multirow[t]{4}{*}{ Tara primers } & $\mathrm{TD}$ & 7 & 5 & 4 & - & 4B & $4 \mathrm{~B}$ & $4 B$ & $4 B$ & - \\
\hline & TLD & 5 & 4 & 3 & - & 4B & 3B & 3B & $2 \mathrm{~B}$ & - \\
\hline & TO & 7 & 6 & 5 & 4 & $4 \mathrm{~B}$ & 3B & $2 \mathrm{~B}$ & $3 \mathrm{~B}$ & 3B \\
\hline & TLO & 7 & 6 & 5 & 4 & $4 \mathrm{~B}$ & 3B & $2 \mathrm{~B}$ & $2 \mathrm{~B}$ & 3B \\
\hline \multirow[t]{4}{*}{ Quebracho primers } & QD & 8 & 7 & 4 & - & $4 \mathrm{~B}$ & $1 \mathrm{~B}$ & $1 \mathrm{~B}$ & OB & - \\
\hline & QLD & 6 & 4 & 3 & - & $4 \mathrm{~B}$ & $1 \mathrm{~B}$ & 1B & 1B & - \\
\hline & $\mathrm{QO}$ & 9 & 7 & 7 & 3 & $4 B$ & $2 B$ & $1 \mathrm{~B}$ & $1 \mathrm{~B}$ & $1 \mathrm{~B}$ \\
\hline & QLO & 6 & 4 & 4 & 3 & $3 B$ & $2 \mathrm{~B}$ & $1 \mathrm{~B}$ & $1 \mathrm{~B}$ & 1B \\
\hline \multirow{2}{*}{$\begin{array}{l}\text { Zinc tetroxychromate } \\
\text { primer }\end{array}$} & $\mathrm{ZD}$ & 9 & 8 & 6 & - & $5 B$ & 1B & 1B & $\mathrm{OB}$ & - \\
\hline & $\mathrm{ZO}$ & 9 & 8 & 6 & 4 & $2 \mathrm{~B}$ & $2 B$ & $1 \mathrm{~B}$ & $1 \mathrm{~B}$ & $1 \mathrm{~B}$ \\
\hline
\end{tabular}


interaction between the tannin fraction and the oxide layer.

3.2.2.3. SAE 1010 steel panels coated with quebracho primers. The rusting degree of QD and QLD coated panels was 7 and 4, respectively, after 3 days in the humidity chamber (Table 2, Supplementary data, Figs. VII and VIII). The rusting degree of QO panels was 9 after the first day and 7 after 5 days of assay, while for QLO systems the qualification was lower (6 and 4, respectively) (Table 2, Supplementary data, Figs. IX and X). These panels were removed after 7 days with a qualification of 3 .

All the samples presented no blisters along the assay.

The adhesion loss of the samples primed with quebracho tannin and its derivative occurred abruptly after 1 day in the chamber (Table 2). QD and QLD coated panels behaved similarly to QO and QLO ones: adhesion was acceptable at the beginning of the test period but after 1 day in the humidity chamber it was almost completely lost and no recovering was observed.

3.2.2.4. SAE 1010 steel panels coated with zinc tetroxychromate primer. ZD coated panels had better performance than the degreased steel panels coated with tannins' based primers, being qualified 9 after 1 day of assay, 8 after 3 days (Supplementary data, Fig. XI) and 6 after 1 week (Table 2). The protection afforded by $\mathrm{ZO}$ was similar to that provided by $\mathrm{ZD}$ and comparable to the performance of $\mathrm{QO}$ (Supplementary data, Fig. XII).

The exposed panels presented no blisters along the assay.

In the case of ZD coated panels, the adhesion loss occurred abruptly after 1 day in the chamber (Table 2). The adhesion between the oxidized panels and zinc tetroxychromate primer was poor from the very beginning of the test (Table 2).

As a trend, the adhesion of tannins primers to the substrate was better than the adhesion of the chromate primer. This fact may be due to the more acidic nature of tannins and their ability to interact with iron ions. Tara tannin primers adhered better than quebracho primers. The chromate primer showed no adherence on the rusted substrate.

\subsubsection{Electrochemical studies}

3.2.3.1. SAE 1010 steel panels without primers. The ionic resistance of the control panels (BD and BO) was very similar $\left(\approx 200 \Omega \times \mathrm{cm}^{2}\right)$ along the whole test period (Figs. 7 and 8).

The corrosion current density (Jc) of the BD panel reached its lower value after $4 \mathrm{~h}$ of immersion; then $\mathrm{Jc}$ was $\approx 10 \mu \mathrm{A} / \mathrm{cm}^{2}$ up to the end of the measurements (Fig. 9). As a trend, Jc of the BO (Fig. 10) panel was higher than Jc for the BD panel. As in the case of the BD panel, the highest Jc was obtained at the beginning of the essay. Afterwards, Jc

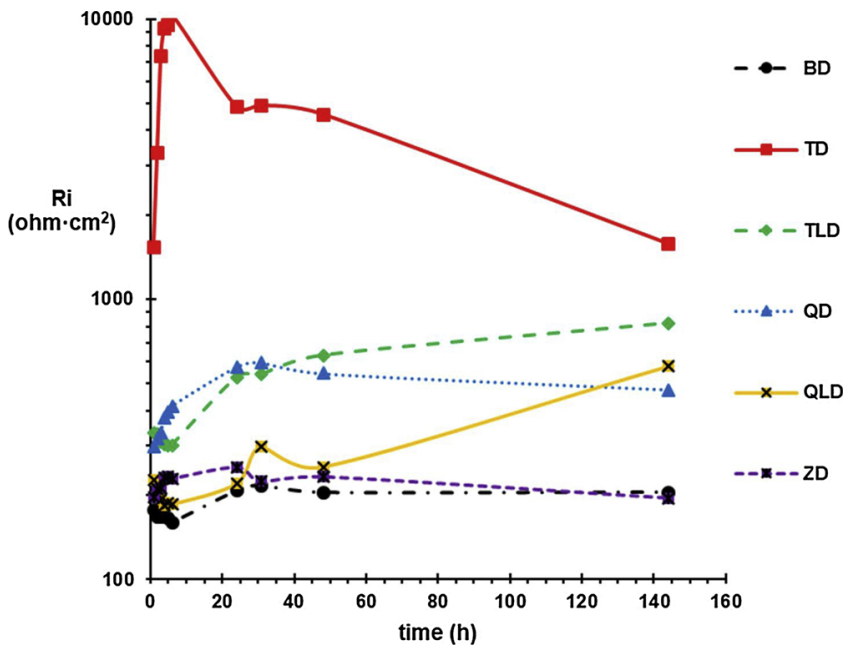

Fig. 7. Ionic resistance values (Ri) as function of time for degreased panels.

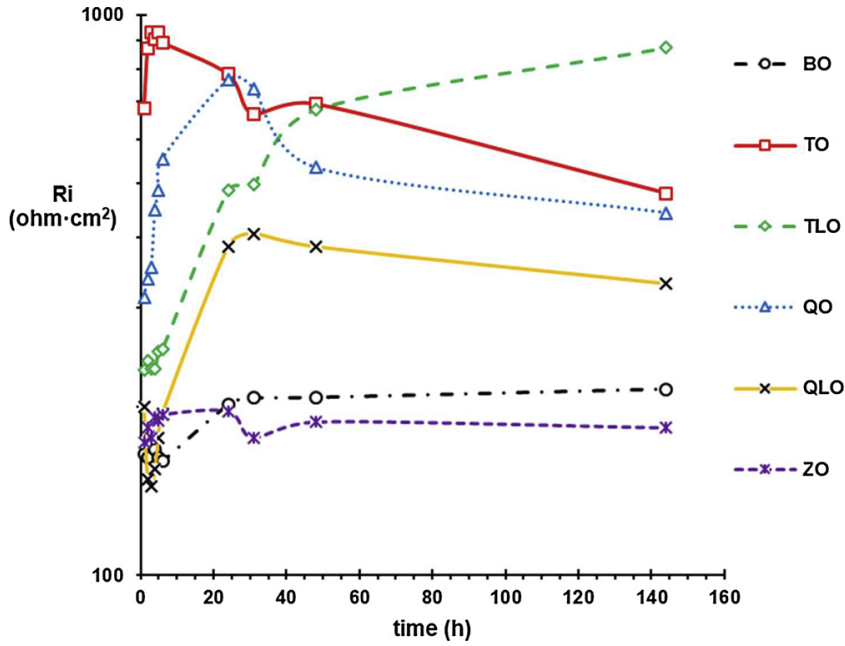

Fig. 8. Ionic resistance values (Ri) as function of time for oxidized panels.

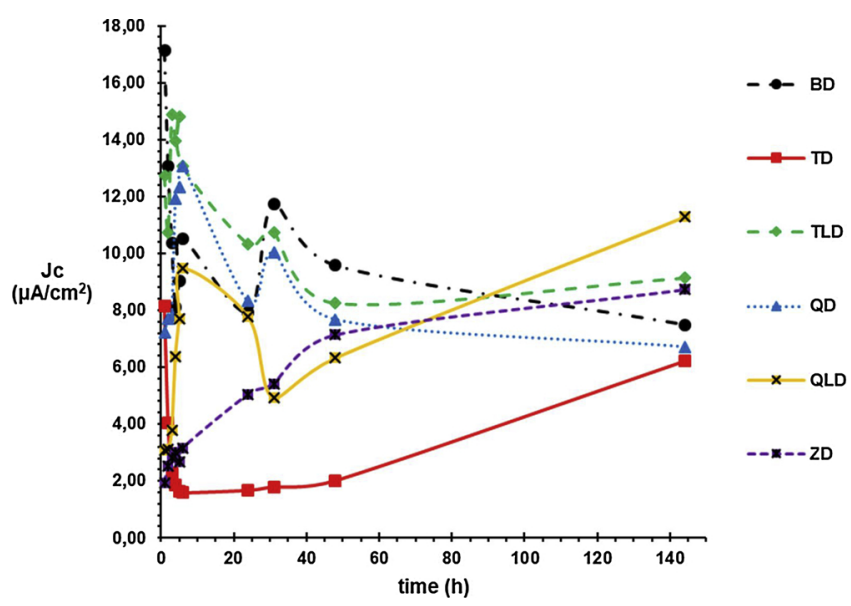

Fig. 9. Corrosion current density values (Jc) as function of time for degreased panels.

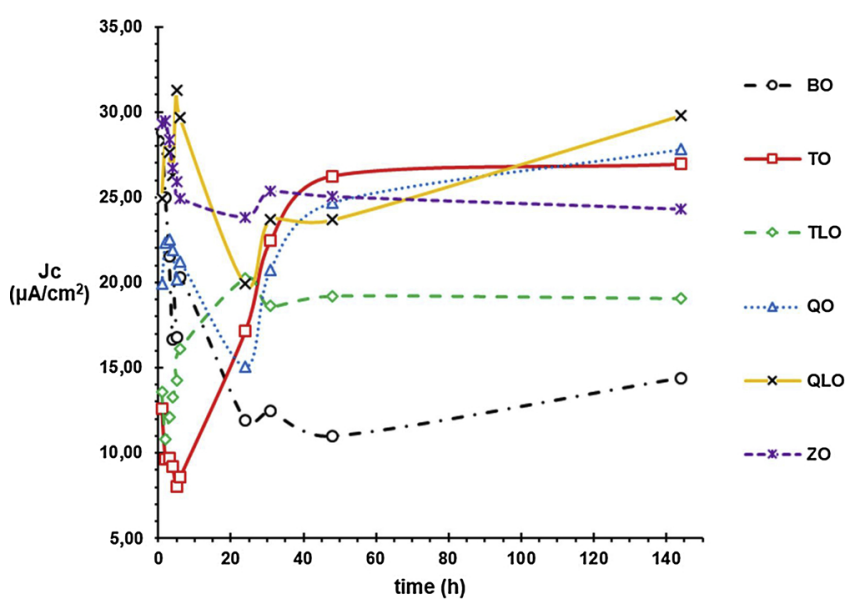

Fig. 10. Corrosion current density values (Jc) as function of time for oxidized panels.

diminished probably due to the formation of a stable oxide layer, but the final value $\left(\approx 15 \mu \mathrm{A} / \mathrm{cm}^{2}\right)$ was higher than that of the BD panel. The higher Jc values obtained for the BO panel may be understood considering that the rusting process left the panel more active.

The corrosion potentials values (Ec) of degreased and previously rusted substrates (BD and BO) were around $-750 \mathrm{mV}$ vs SCE (Figs. 11 


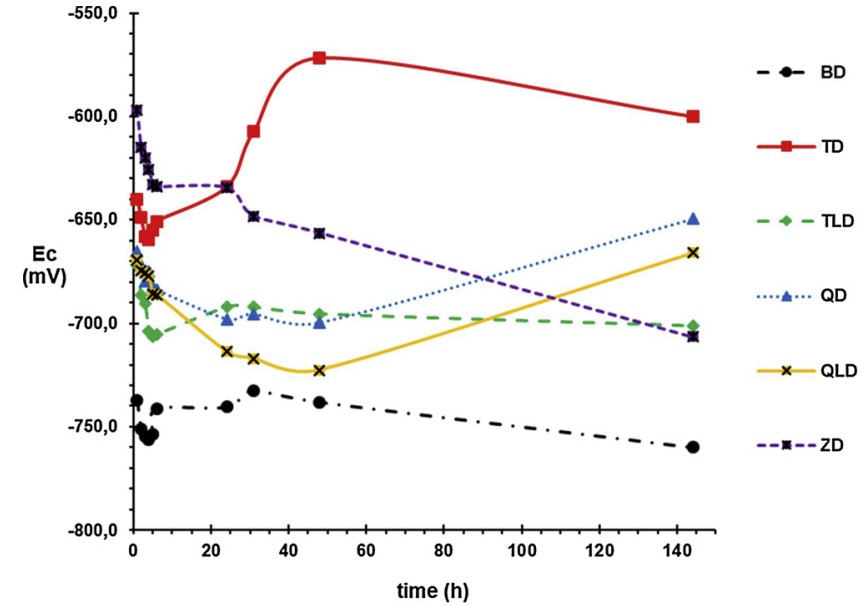

Fig. 11. Corrosion potential (Ec) as function of time for degreased panels.

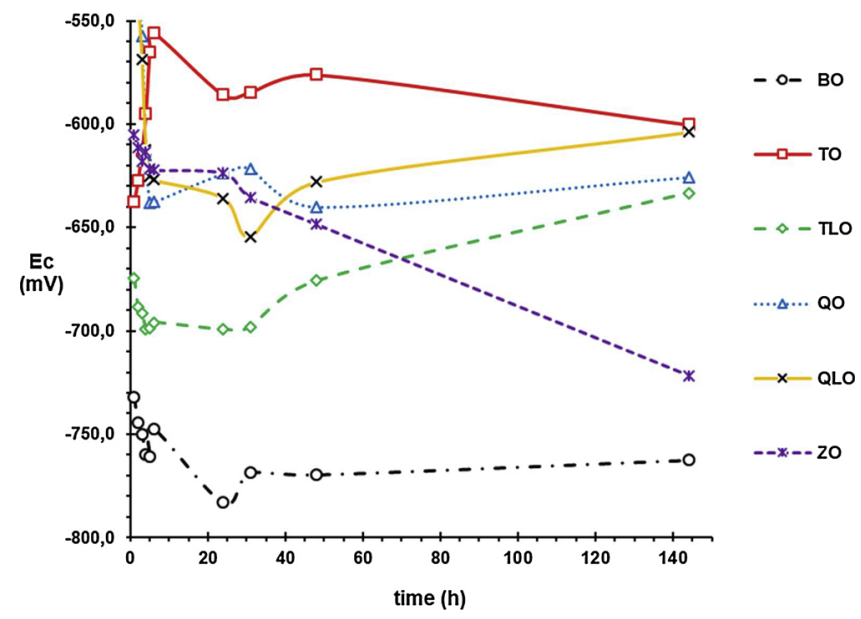

Fig. 12. Corrosion potential (Ec) as function of time for oxidized panels.

and 12) and corresponded to steel undergoing corrosion.

3.2.3.2. SAE 1010 steel panels coated with tara primers. The ionic resistance for the TD coated panel was almost an order of magnitude higher than the values corresponding to the control panel $\mathrm{BD}$, with a maximum close to $10^{4} \mathrm{ohm} \times \mathrm{cm}^{2}$ after $6 \mathrm{~h}$ of immersion (Fig. 7). This exceptional behaviour may be due to the interaction between the substrate and the tannin which, in turn, resulted in a good adhesion which was sustained along time. The values for the TLD coated panel were only 2-4 times higher than those corresponding to BD. The TO coated panel presented ionic resistance values 2-4 times higher than those corresponding to the control panel $\mathrm{BO}$, reaching a maximum at 5-6 $\mathrm{h}$ followed by a progressive decay (Fig. 8). The Ri values for the TLO panel were similar to the values for the control BO during the first $6 \mathrm{~h}$ of immersion and, then, presented values similar to those of the TO panel after $48 \mathrm{~h}$ of exposure. From the foregoing discussion, it is clear that the primers did not protect steel due to their barrier properties.

The TD coated panel showed the best anticorrosion behaviour. The increase in the ionic resistance together with the nature of the conversion layer correlated with the decrease in the corrosion current density of the TD panel during the first $6 \mathrm{~h}$ of immersion (Fig. 9). Then, the Jc values were almost an order of magnitude lower than those of BD. Jc values for the TLD panel were similar to those of BD all along the test (Fig. 9). In regards of the TO panel, Jc values were lower than those of BO up to $18 \mathrm{~h}$ of immersion; afterwards this situation was reversed. In the case of the TLO panel, its behaviour was similar to the observed for TO: Jc was lower than the corresponding to the control $\mathrm{BO}$ during the first $11 \mathrm{~h}$ but, then, the values increased to double than those of BO (Fig. 10).

At the beginning of the immersion, Ec of all coated panels were more positive than the respective controls. The panels TD and TO presented the more positive values $(\approx-650 \mathrm{mV}$ ) (Figs. 11 and 12 ). In the case of the panel TD, Ec increased after $24 \mathrm{~h}$; while, for panel TO, Ec increased continuously reaching a plateau at $\approx-550 \mathrm{mV}$ after $6 \mathrm{~h}$ of assay. Ec of panels TLD and TLO was $\approx-740 \mathrm{mV}$ and varied slightly as time went on.

3.2.3.3. SAE 1010 steel panels coated with quebracho primers. The ionic resistance values of the panels with primers based on quebracho tannin (QD, QO, QLD and QLO) were higher (3-4 times) than the corresponding controls, BD and BO (Figs. 7 and 8).

As a trend, the panels QD and QLD presented Jc values higher than those of the control BD, except at the beginning of the test (Figs. 9 and 10 ). The Jc values for the panel QO were close to the corresponding control BO at the first $24 \mathrm{~h}$, and then increased to $\approx 25 \mu \mathrm{A} / \mathrm{cm}^{2}$ at the end of the experiment. The corrosion current density values of the panel QLO were always higher than those of $\mathrm{BO}$, with values of $\approx 30 \mu \mathrm{A} / \mathrm{cm}^{2}$ at the beginning and the end of the immersion. It can be concluded, therefore, that the primers with quebracho tannin and its derivative did not inhibit substrate corrosion.

During the first $6 \mathrm{~h}$ of immersion the panels QD and QLD presented Ec values of $\approx-675 \mathrm{mV}$, and after that time the panel QLD exhibited corrosion potentials slightly more negatives than the panel QD (Figs. 11 and 12). The panels QO and QLO presented Ec of $\approx-500 \mathrm{mV}$ at the beginning of the experiment; then their corrosion potential dropped off to $\approx-625 \mathrm{mV}$ during the first $6 \mathrm{~h}$, stood at this value up to the end of the essay. In every case Ec values corresponded to steel undergoing corrosion.

3.2.3.4. SAE 1010 steel panels coated with zinc tetroxychromate primer. During the first $24 \mathrm{~h}$, the Ri of the coated panels ZD and ZO was slightly higher than the corresponding controls, BD and BO respectively. Afterwards, $\mathrm{Ri}$ values approached $\left(\approx 200 \Omega \times \mathrm{cm}^{2}\right)$ (Figs. 7 and 8).

Jc values of the panel ZD were lower than the $\mathrm{BD}$ one, especially during the first $6 \mathrm{~h}$ of immersion ( $\approx 3 \mu \mathrm{A} / \mathrm{cm}^{2}$ ) (Fig. 9). The corrosion current density values for the $\mathrm{ZO}$ panel (Fig. 10) were higher than the control BO $\left(\approx 25-30 \mu \mathrm{A} / \mathrm{cm}^{2}\right)$. This fact pointed out that chromate did not perform adequately on rusted surfaces.

$\mathrm{ZD}$ and $\mathrm{ZO}$ panels presented Ec more positive than the corresponding controls, especially during the first $30 \mathrm{~h}$ of immersion where the values fluctuated around $-620 \mathrm{mV}$ (Figs. 11 and 12). Then the corrosion potentials were displaced to more negative values $(\approx$ $-700 \mathrm{mV}$ ) after $144 \mathrm{~h}$ of assay.

Tannin and different "tannates" were tested by several authors and in several conditions and formulations [6,7,9,15,20,21,32,33]. Despite comparison among the results is difficult because substrate preparation, primer formulations, coating thickness and tests are different, they all claimed that the performance of the protective films is similar to chromate- or phosphate-based primer, used as control and tannin and "tannates" can be used to replace traditional anticorrosive pigments. In this sense, the results exposed above are comparable. Besides, more research should be done taking into account that tannins are extracted from natural and renewable resources and that tannin and tannin-based compounds can protect steel in several conditions [11,34-36].

\section{Conclusions}

i Lanthanum "tannates" can be prepared employing tara or quebracho tannins and lanthanum nitrate solution; they can be incorporated in primers formulation.

ii Tannin based primers can be applied on low roughness steel panels with good adhesion, similar to that of zinc tetroxychromate primer. 
Tannin based primers applied on oxidized steel panels had higher adhesion than zinc tetroxychromate primer.

iii The electrochemical tests showed the tannins and "tannate" primers had better barrier properties than the zinc tetroxychromate one.

iv In general, the corrosion current density of primed degreased steel was lower than in the case of steel protected with the zinc tetroxychromate primer. In the case of oxidized steel, only the tara lanthanum "tannate" provided lower corrosion current density.

\section{Appendix A. Supplementary data}

Supplementary material related to this article can be found, in the online version, at doi:https://doi.org/10.1016/j.porgcoat.2019.02.003.

\section{References}

[1] B.N. Popov, Atmospheric corrosion, Corrosion Engineering, Elsevier, 2015, pp. $451-480$

[2] J. Alcántara, B. Chico, I. Díaz, D. de la Fuente, M. Morcillo, Airborne chloride deposit and its effect on marine atmospheric corrosion of mild steel, Corros. Sci. 97 (2015) 74-88.

[3] E.W. Beale, Temporary protectives, in: L.L. Shreir (Ed.), Corrosion, NewnesButterworths, London, 1976pp. 17:21-17:29.

[4] V.S. Saji, Progress in rust converters, Prog. Org. Coat. 127 (2019) 88-99.

[5] G. Matamala, W. Smeltzer, R. Benevente, Pine Tannin Rust Converter for Steel Protecion by Painting, Universidad de Concepción, Concepción, Chile, 1989.

[6] L.F. Montoya, D. Contreras, A.F. Jaramillo, C. Carrasco, K. Fernández, B. Schwederski, D. Rojas, M.F. Melendrez, Study of anticorrosive coatings based on high and low molecular weight polyphenols extracted from the Pine radiata bark, Prog. Org. Coat. 127 (2019) 100-109.

[7] A.V. Zmozinski, R.S. Peres, K. Freiberger, C.A. Ferreira, S.M.M. Tamborim, D.S. Azambuja, Zinc tannate and magnesium tannate as anticorrosion pigments in epoxy paint formulations, Prog. Org. Coat. 121 (2018) 23-29.

[8] Y. Shirmohammadli, D. Efhamisisi, A. Pizzi, Tannins as a sustainable raw material for green chemistry: a review, Ind. Crops Prod. 126 (2018) 316-332.

[9] S. Flores Merino, J.J. Caprari, L. Vasquez Torres, L. Figueroa Ramos, A. Hadzich Girola, Inhibitive action of tara tannin in rust converter formulation, Anti-corrosion Methods Mater. 64 (2017) 136-147.

[10] A.A. Rahim, M.J. Kassim, E. Rocca, J. Steinmetz, Mangrove (Rhizophora apiculata) tannins: an eco-friendly rust converter, Corros. Eng. Sci. Technol. 46 (2011) 425-431.

[11] A.A. Rahim, E. Rocca, J. Steinmetz, M. Jain Kassim, Inhibitive action of mangrove tannins and phosphoric acid on pre-rusted steel via electrochemical methods, Corros. Sci. 50 (2008) 1546-1550.

[12] A.A. Rahim, E. Rocca, J. Steinmetz, M.J. Kassim, R. Adnan, M. Sani Ibrahim, Mangrove tannins and their flavanoid monomers as alternative steel corrosion inhibitors in acidic medium, Corros. Sci. 49 (2007) 402-417.

[13] T.K. Ross, R.A. Francis, The treatment of rusted steel with mimosa tannin, Corros. Sci. 18 (1978) 351-361.

[14] M.N. Mohamad Ibrahim, M.Y. Nor Nadiah, A.A. Amirue, Extraction of tannin from oil Palm empty fruit bunch as a rust deactivator, Regional Symposium on Chemical Engineering (2005) 197-201.
[15] A. Hadzich, S. Flores, J. Caprari, R. Romagnoli, Study of zinc tannates prepared with Tara powder (Caesalpinia spinosa) as anticorrosive pigments in alkyd paints and wash primer formulations, Prog. Org. Coat. 117 (2018) 35-46.

[16] J. Iglesias, E. García de Saldaña, J.A. Jaén, On the tannic acid interaction with metallic Iron, Hyperfine Interact. 134 (2001) 109-114.

[17] J.A. Jaén, J. De Obaldía, M.V. Rodríguez, Application of Mössbauer spectroscopy to the study of tannins inhibition of iron and steel corrosion, Hyperfine Interact. 202 (2011) 25-38.

[18] S. Yahya, A.M. Shah, A.A. Rahim, N.H. Abd Aziz, R. Roslan, Phase transformation of rust in the presence of various tannins, J. Phys. Sci. 19 (2008) 31-41.

[19] P.J. DesLauriers, Rust convertion coatings, Mater. Perform. 26 (1987) 35-40.

[20] O. D’Alessandro, G. Selmi, C. Deyá, A. Di Sarli, R. Romagnoli, Lanthanum derivative from "Tara" tannin for steel temporary protection, Ind. Eng. Chem. Res. 57 (2018) 3215-3226.

[21] O. D’Alessandro, G.J. Selmi, C. Deyá, A. Di Sarli, R. Romagnoli, Formulation and Assessment of a Wash Primer Containing Lanthanum "Tannate" for Steel Temporary Protection, Journal of Material Engineering and Performance 27 (2018) 687-704.

[22] R. Frentzel-Beyme, Lung cancer mortality of workers employed in chromate pigment factories, J. Cancer Res. Clin. Oncol. 105 (1983) 183-188.

[23] F.H. Firsching, J.C. Kell, The Solubility of the Rare-Earth-Metal Phosphates in Sea Water, J. Chem. Eng. Data 38 (1993) 132-133.

[24] M.I. Karyakina, E. Kuzmak, Protection by organic coatings: criteria, testing methods and modelling, Prog. Org. Coat. 18 (1990) 325-388.

[25] G.W. Walter, A critical review of d.c. electrochemical tests for painted metals, Corros. Sci. 26 (1986) 39-47.

[26] H. Antony, S. Peulon, L. Legrand, A. Chaussé, Electrochemical synthesis of lepidocrocite thin films on gold substrate-EQCM, IRRAS, SEM and XRD study, Electrochim. Acta 50 (2004) 1015-1021.

[27] H.D. Ruan, R.L. Frost, J.T. Kloprogge, L. Duong, Infrared spectroscopy of goethite dehydroxylation: III. FT-IR microscopy of in situ study of the thermal transformation of goethite to hematite, Spectrochim. Acta A. Mol. Biomol. Spectrosc. 58 (2002) 967-981.

[28] M. Ishii, M. Nakahira, Infrared absorption spectra and cation distribution in ( $\mathrm{Mn}, \mathrm{Fe})$ 304, Solid State Commun. 11 (1972) 209-212.

[29] F. dos Santos Grasel, M. Flôres Ferrão, C.R. Wolf, R.A. Ligabue, Characterization of natural tanning extracts by FTIR and multivariate analysis, XXXIII IULTCS Congress (2015) Paper 067.

[30] M.A. Pantoja-Castro, H. González-Rodríguez, Study by infrared spectroscopy and thermogravimetric analysis of tannins and tannic acid, Rev. Latinoamer. Quím. 39 (2011) 107-112.

[31] R. Zhang, L. Li, J. Liu, Synthesis and characterization of ferric tannate as a novel porous adsorptive-catalyst for nitrogen removal from wastewater, RSC Adv. 5 (2015) 40785-40791.

[32] J.K. Mohd, A.R. Afidah, A.I. Mohd, Anti-corrosive performance of wash primer based on mangrove tannin, I5h Symposium of Malaysian Chemical Engineers SOMChE (2001) 323-327.

[33] O.R. Pardini, J.I. Amalvy, A.R. Di Sarli, R. Romagnoli, V.F. Vetere, Formulation and testing of a waterborne primer containing chestnut tannin, J. Coat. Technol. Res. 73 (2001) 99.

[34] E. Kusmierek, E. Chrzescijanska, Tannic acid as corrosion inhibitor for metals and alloys, Mater. Corros. 66 (2015) 169-174.

[35] B. Qian, B. Hou, M. Zheng, The inhibition effect of tannic acid on mild steel corrosion in seawater wet/dry cyclic conditions, Corros. Sci. 72 (2013) 1-9.

[36] M. Dargahi, A.L.J. Olsson, N. Tufenkji, R. Gaudreault, Green Technology: TanninBased Corrosion Inhibitor for Protection of Mild Steel, Corrosion 71 (2015) 1321-1329. 